\title{
Primary squamous cell carcinoma of pancreas: a population-based study
}

\author{
Wen-Xing Qin ${ }^{1 \#}$, Ying $\mathrm{Wu}^{1 \#}$, Jun Liu ${ }^{1,2 \#}$, Bao-Dong Qin ${ }^{1}$, Ke Liu ${ }^{1}$, Xiao-Dong Jiao ${ }^{1}$, Zhan Wang ${ }^{1}$, \\ Wan-Sheng Chen ${ }^{2}$, Yuan-Sheng Zang' \\ ${ }^{1}$ Department of Medical Oncology, Changzheng Hospital, Naval Medical University, Shanghai, China; ${ }^{2}$ Department of Pharmacy, Changzheng \\ Hospital, Naval Medical University, Shanghai, China \\ Contributions: (I) Conception and design: WX Qin, YS Zang, BD Qin, XD Jiao; (II) Administrative support: YS Zang, WS Chen; (III) Provision \\ of study materials or patients: J Liu, Y Wu, K Liu; (IV) Collection and assembly of data: J Liu, Y Wu, XD Jiao, Z Wang; (V) Data analysis and \\ interpretation: WX Qin, Y Wu, J Liu; (VI) Manuscript writing: All authors; (VII) Final approval of manuscript: All authors. \\ \#These authors contributed equally to this work. \\ Correspondence to: Wan-Sheng Chen. Department of Pharmacy, Changzheng Hospital, Naval Medical University, Shanghai 200003, China. Email: \\ chenwansheng@smmu.edu.cn; Yuan-Sheng Zang. Department of Medical Oncology, Changzheng Hospital, Naval Medical University, 64 Hetian \\ Road, Shanghai, China. Email: doctorzangys@163.com.
}

Background Primary squamous cell carcinoma of pancreas (SCCP) is an extremely rare pathological subtype of pancreatic cancer of ductal origin. Due to its rarity, most previous studies on SCCP focused on case reports or series and the clinio-pathological characteristics of SCCP patients remain unclear.

Methods: A retrospective analysis of SCCP patients registered in the Surveillance, Epidemiology and End Results (SEER) database from 1988 to 2016 were performed, and clinical characteristics and prognosis of these patients were also further determined.

Results: A total of 373 patients diagnosed with SCCP were identified. Most SCCP patients 154/243 (63.4\%) SCCP patients had distant metastases. The prognosis of SCCP patients was poor with a median overall survival (mOS) of only 3.0 months (95\% CI, 2.0-5.0). The 6-month, 1-year and 2-years survival rate were $25.6 \%, 13.2 \%$ and $5.7 \%$, respectively. The prognosis of SCCP patients became much worse with the increasing age $(\mathrm{P}=0.01)$ and distant metastases $(\mathrm{P}<0.01)$. Cancer-directed surgery, chemotherapy and radiotherapy could significantly prolong the survival time for SCCP patients $(\mathrm{P}<0.01$ for all). Multivariate Cox analysis showed that only distant metastases were independent prognostic factors of worse survival in SCCP patients ( $\mathrm{HR}=1.58,95 \% \mathrm{CI}, 1.18-2.12)$. Conversely, both cancer-directed surgery and chemotherapy were an independent protective factor that decreased the risk of death by $66 \%$ (HR $=0.18,95 \%$ CI, 0.11-0.29) and $46 \%$ (HR $=0.54,95 \%$ CI, 0.43-0.68) for SCCP patients.

Conclusions: SCCP is a rare type of pancreatic malignancies with poor prognosis. The present study could provide some useful information for future management and prospective studies for SCCP patients.

Keywords: Pancreatic cancer; squamous cell carcinoma; Surveillance, Epidemiology and End Results (SEER) database; prognosis

Submitted Mar 08, 2020. Accepted for publication Sep 10, 2020.

doi: $10.21037 /$ gs-20-317

View this article at: http://dx.doi.org/10.21037/gs-20-317 


\section{Introduction}

Primary squamous cell carcinoma of pancreas (SCCP) is an extremely rare pathological subtype of pancreatic cancer of ductal origin, accounting for approximately $1 \%$ of all pancreatic malignancies, with a reported incidence range of $0.5 \%$ to $5 \%(1,2)$. Because of its rarity, SCCP is typically diagnosed only after excluding other primary sources of cancer and should be further confirmed a lack of glandular component. The pathological mechanism of SCCP was not totally clear. Theoretically, the pancreas is totally devoid of squamous cells, the previous studies have suggested SCCP may arise from ductules that have undergone squamous metaplasia secondary to chronic pancreatitis $(3,4)$. Due to the finding that most SCCP are not related with chronic inflammation, SCCP has been thought to result from malignant transformation of squamous metaplastic zones in the pancreatic ductal epithelium (5). Other possibility for SCCP development included malignant change in a primitive cell and an aberrant squamous cells in pancreas (6).

Specific risk factors for SCCP have not been fully defined. The same risk factors for adenocarcinoma appear to also be related with SCCP. The symptoms of SCCP is similar to pancreatic adenocarcinoma, including abdominal pain, back pain, jaundice, anorexia (7). Previous study reported the enhancement of the tumor with contrast computed tomography and blush patterns with angiography could be used to differentiate SCCP from pancreatic adenocarcinoma $(2,8)$. Analysis of the biologic behavior of SCCP from previous studies observed its propensity to affect older patients, presence of metastasis at diagnosis, low response to chemotherapy and radiotherapy, and poor prognosis (9).

Due to its rarity, most previous studies on SCCP focused on case reports or series (5,7-9). To identify its clinicopathological characteristics and prognosis, we performed a retrospective analysis of SCCP patients registered in the Surveillance, Epidemiology and End Results (SEER) database from 1988 to 2016, and we determine the clinical characteristics and prognosis of these patients. We present the following article in accordance with the STROBE reporting checklist (available at http:// dx.doi.org/10.21037/gs-20-317).

\section{Methods}

\section{Participants}

The data of SCCP patients for this analysis were obtained from the Surveillance, Epidemiology, and End Results (SEER) database, which is a publicly available cancer registry maintained by the National Cancer Institute of Unite States and collects information including cancer incidence and survival of approximately $28 \%$ of the US population. All patients diagnosed with SCCP (ICD-0-3: 8070/8071/8072/8073/8074/8075) from SEER databased between 1988 and 2016 were identified. Demographic information and clinical-pathological characteristics for each SCCP patient were isolated using SEER*stat 8.3.6 software. Besides, the overall survival time of each SCCP patient was also extracted from SEER database. Because the SEER data are de-identified before release, institutional review board approval and informed consent are not required for this study. All authors have signed the research agreement form and received permission to access to SEER database. The study was conducted in accordance with the Declaration of Helsinki (as revised in 2013).

\section{Statistical analysis}

The clinical-pathological characteristics of all SCCP patients were described with count and percentage. The clinical Survival analysis stratified by each feature were performed using Kaplan-Meier curves and Log-Rank test. Univariate and multivariate Cox regression analysis were used to determine potential prognostic factors correlated with survival. All statistical analyses were performed using MedCalc software (Mariakerke, Belgium).

\section{Results}

\section{Patients characteristics}

A total of 373 patients diagnosed with SCCP were identified from SEER database between 1988 and 2016 (Table 1). 137,232 patients with pancreatic ductal adenocarcinoma (PDAC) were identified in the same period. The incidence ratio of SCCP to PDAC is $1: 368$. The average age at diagnose was $69.4 \pm 11.8$ years old. Most of lesion were located in head of pancreas. Patients had a poorly pathological differentiation. Among all patients with known stage status, $65.3 \%(154 / 237)$ of SCCP patients were diagnosed with IV stage, 236/349 patients were diagnosed with distant stage according to SEER historic stage classification. 154/243 (63.4\%) SCCP patients had distant metastases and 100 out of 224 patients had lymph node metastases. As for treatment, a majority (341/372) of 
Table 1 Clinico-pathological characteristics of the 373 patients with SCCP

\begin{tabular}{|c|c|}
\hline Characteristics & Total \\
\hline Age (year) & $69.4 \pm 11.8$ \\
\hline \multicolumn{2}{|l|}{ Gender } \\
\hline Female & 175 \\
\hline Male & 198 \\
\hline \multicolumn{2}{|l|}{ Ethnicity } \\
\hline White & 283 \\
\hline Black & 52 \\
\hline Other & 36 \\
\hline Unknown & 2 \\
\hline \multicolumn{2}{|l|}{ Pathological differentiation } \\
\hline Well & 10 \\
\hline Moderate & 24 \\
\hline Poor & 119 \\
\hline Undifferentiated & 6 \\
\hline Unknown & 214 \\
\hline \multicolumn{2}{|l|}{ Summary stage } \\
\hline Distant & 236 \\
\hline Regional & 93 \\
\hline Localized & 20 \\
\hline Unstaged & 24 \\
\hline \multicolumn{2}{|l|}{ Primary site } \\
\hline Head of pancreas & 160 \\
\hline Body of pancreas & 50 \\
\hline Tail of pancreas & 67 \\
\hline Overlapping lesion of pancreas & 30 \\
\hline Unknown & 66 \\
\hline \multicolumn{2}{|l|}{ TNM stage } \\
\hline 1 & 11 \\
\hline II & 43 \\
\hline III & 29 \\
\hline IV & 154 \\
\hline Unknown & 136 \\
\hline
\end{tabular}

Table 1 (continued)
Table 1 (continued)

\begin{tabular}{|c|c|}
\hline Characteristics & Total \\
\hline \multicolumn{2}{|l|}{ Tumor size } \\
\hline T1 & 0 \\
\hline T2 & 50 \\
\hline T3 & 88 \\
\hline $\mathrm{T} 4$ & 60 \\
\hline Unknown & 172 \\
\hline \multicolumn{2}{|c|}{ Lymph node metastases } \\
\hline No & 114 \\
\hline N1 & 100 \\
\hline Unknown & 159 \\
\hline \multicolumn{2}{|c|}{ Distant Metastases } \\
\hline MO & 89 \\
\hline M1 & 154 \\
\hline Unknown & 130 \\
\hline \multicolumn{2}{|l|}{ Surgery } \\
\hline Yes & 31 \\
\hline No & 341 \\
\hline Unknown & 1 \\
\hline \multicolumn{2}{|l|}{ Radiation } \\
\hline Yes & 54 \\
\hline No & 319 \\
\hline \multicolumn{2}{|l|}{ Chemotherapy } \\
\hline Yes & 159 \\
\hline No/unknown & 214 \\
\hline
\end{tabular}



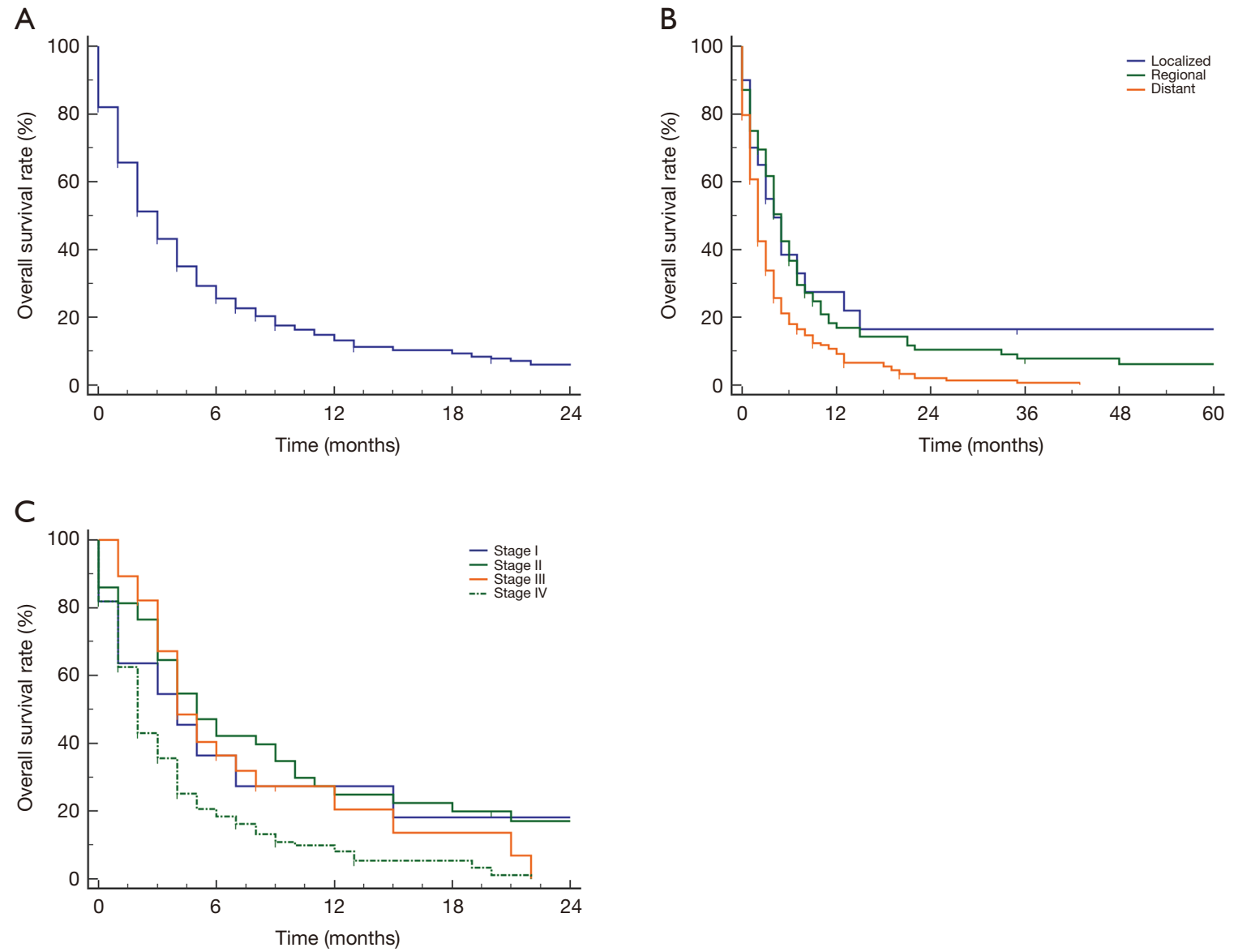

Figure 1 the overall survival of 373 SCCP patients. (A) overall survival; (B) stratified by SEER stage; (C) stratified by TNM stage. SCCP, squamous cell carcinoma of pancreas.

SCCP patients did not receive surgery and 159 out of 373 patients had a history of receiving chemotherapy.

\section{Patients survival}

The prognosis of SCCP patients was poor with a mOS of only 3.0 months (95\% CI, 2.0-5.0 months). The 6-month, 1 -year and 2-years survival rate were $25.6 \%, 13.2 \%$ and $5.7 \%$, respectively (Figure 1A). SCCP patient with advanced stage had significantly shorter survival time than other patients. SCCP patients with distant stages had significantly poorer prognosis than those with localized or regional stage ( $\mathrm{P}<0.01$ for both), but no significantly difference in survival time between patients with localized and regional stage $(\mathrm{P}=0.65)$ (Figure $1 B)$. SCCP patients with distant stages only had a mOS of 2.0 months with 6-months, 1-years survival rate of $17.9 \%, 9.2 \%$. Similar results could be observed in patients with different TNM stages. SCCP patients with IV stage had the shortest survival time than other stages, and no SCCP patients with IV stage could survival more than 21 months with only a $18.4 \%$ 6-month OS rate (Figure 1C).

\section{Features influencing prognosis}

The prognosis of SCCP patients became much worse with the increasing age $(\mathrm{P}=0.01)$ (Figure $2 A)$, older patients have significantly much shorter mOS than younger patients $(3.0$ vs. 2.0 months). The SCCP patients with distant metastases also had significantly shorter mOS than those without distant metastases (mOS: 2.0 vs. 5.0 months, $\mathrm{P}<0.01$ ) (Figure $2 B$ ). In addition, no significant associations between race $(\mathrm{P}=0.14)$, gender $(\mathrm{P}=0.82)$, pathological grade $(\mathrm{P}=0.75)$, lesion site $(\mathrm{P}=0.40)$, $T$ stage $(\mathrm{P}=0.98), \mathrm{N}$ stage $(\mathrm{P}=0.47)$ and prognosis were observed (Figure $\mathrm{S} 1$ ). 

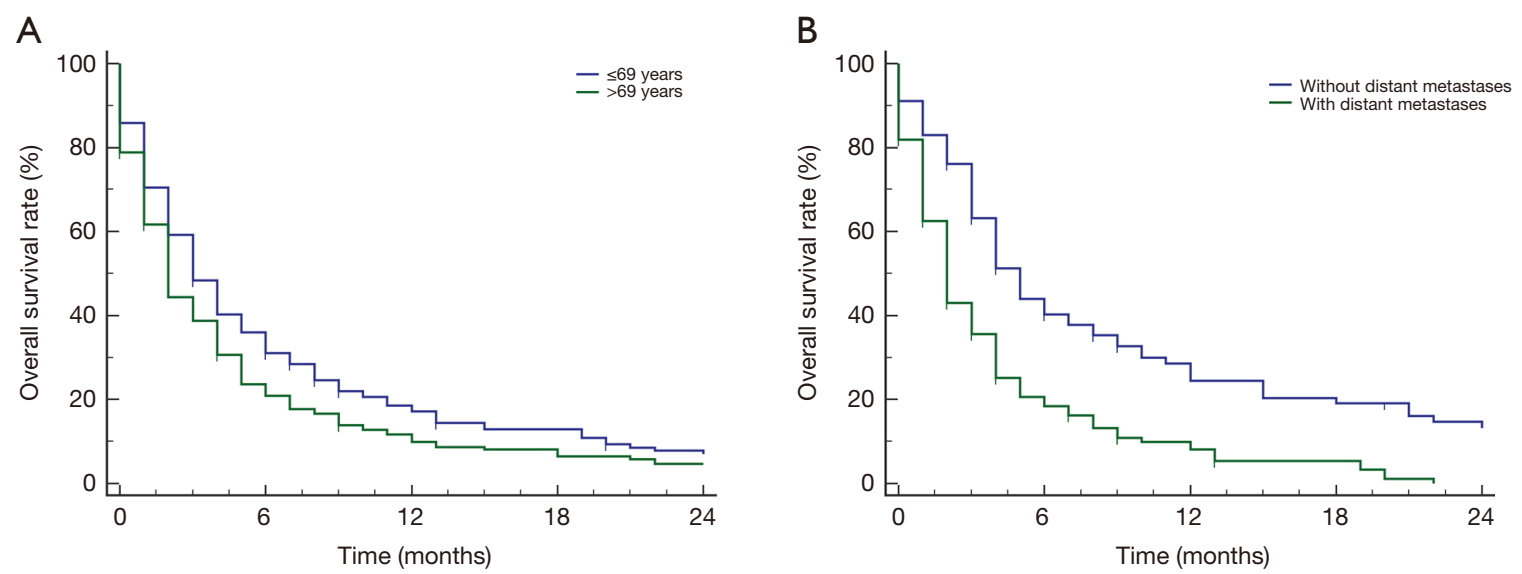

Figure 2 the effect of clinio-pathological features on prognosis in SCCP patients. (A) age; (B) distant metastases. SCCP, squamous cell carcinoma of pancreas.

\section{Effect of treatment on prognosis}

Figure $3 A$ shows that cancer-directed surgery significantly could prolong the survival time for SCCP patients $(\mathrm{P}<0.01$, mOS: $10.0 \mathrm{~m} v s .2 .0 \mathrm{~m})$. Among the SCCP patients who received surgery, the 1-, 2-, and 3-year survival rate was $44.6 \%, 34.3 \%, 22.8 \%$. The mOS of SCCP patients receiving chemotherapy was 5.0 months (95\% CI, 4.0-6.0), while patients without chemotherapy only had 1.0 months of OS (95\% CI, 1.0-2.0) (Figure 3B). Similarly, the survival analysis also showed that SCCP patients who received radiotherapy had significant longer overall survival time than those patients without radiotherapy $(5.0 v s .2 .0$ months; $\mathrm{P}<0.01$; Figure 3C).

\section{Univariate and multivariate Cox proportional bazard analyses}

Further, the characteristics potentially influencing prognosis were determined using univariate and multivariate Cox proportional hazards analysis, and Table 2 shows that older age and distant metastases were significantly associated with poor prognosis $(\mathrm{P}<0.05$ for all, Table 2$)$. The use of surgery, radiotherapy as well as chemotherapy was significantly associated with prolonged overall survival $(\mathrm{P}<0.01$ for all). Multivariate Cox analysis showed that only distant metastases were independent prognostic factors of worse survival in SCCP patients. Conversely, both cancer-directed surgery and chemotherapy were an independent protective factor that decreased the risk of death by $66 \%(\mathrm{HR}=0.18$, 95\% CI, 0.11-0.29) and 46\% (HR $=0.54,95 \%$ CI, $0.43-$
0.68) for SCCP patients.

\section{Discussion}

The most common malignancy located in the pancreas are of ductal cell origin, including PDCA and SCCP, with the vast majority being PDCA. Although overestimation of incidence of SCCP due to erroneous categorization of adenosquamous carcinoma as SCCP, SCCP have a low incidence reported less than $5 \%$ of all pancreatic cancers. Due to its rarity, the clinio-pathological characteristics of SCCP patients remain unclear. In the present study, we have performed a population-based study from SEER database to define the clinical characteristics and prognosis for these patients.

Previous studies reported that SCCP patients tend to occur in older people. One study including 25 SCCP suggested that mean age at diagnosis of SCCP was 62 years ranged from 33-80 years (2). Another analysis of 6 SCCP patients yielded a mean age of 65 years (10). Some previous studies revealed that $92 \%$ of SCCP occur in individuals over 50 years old (11-13). Makarova-Rusher et al. conducted a population-based study using the data of 214 SCCP patients and found higher SCCP incidence rates in older age groups (14). The data of the present study were in consistent with previous data. In the present study, the average age of all 373 SCCP patients were 69 years ranged from 39 years to 93 years and $78.0 \%$ of cases were more than 60 years old. Besides, the previous analysis of 25 SCCP cases did not show a significant sex preference, and SCCP seems to 

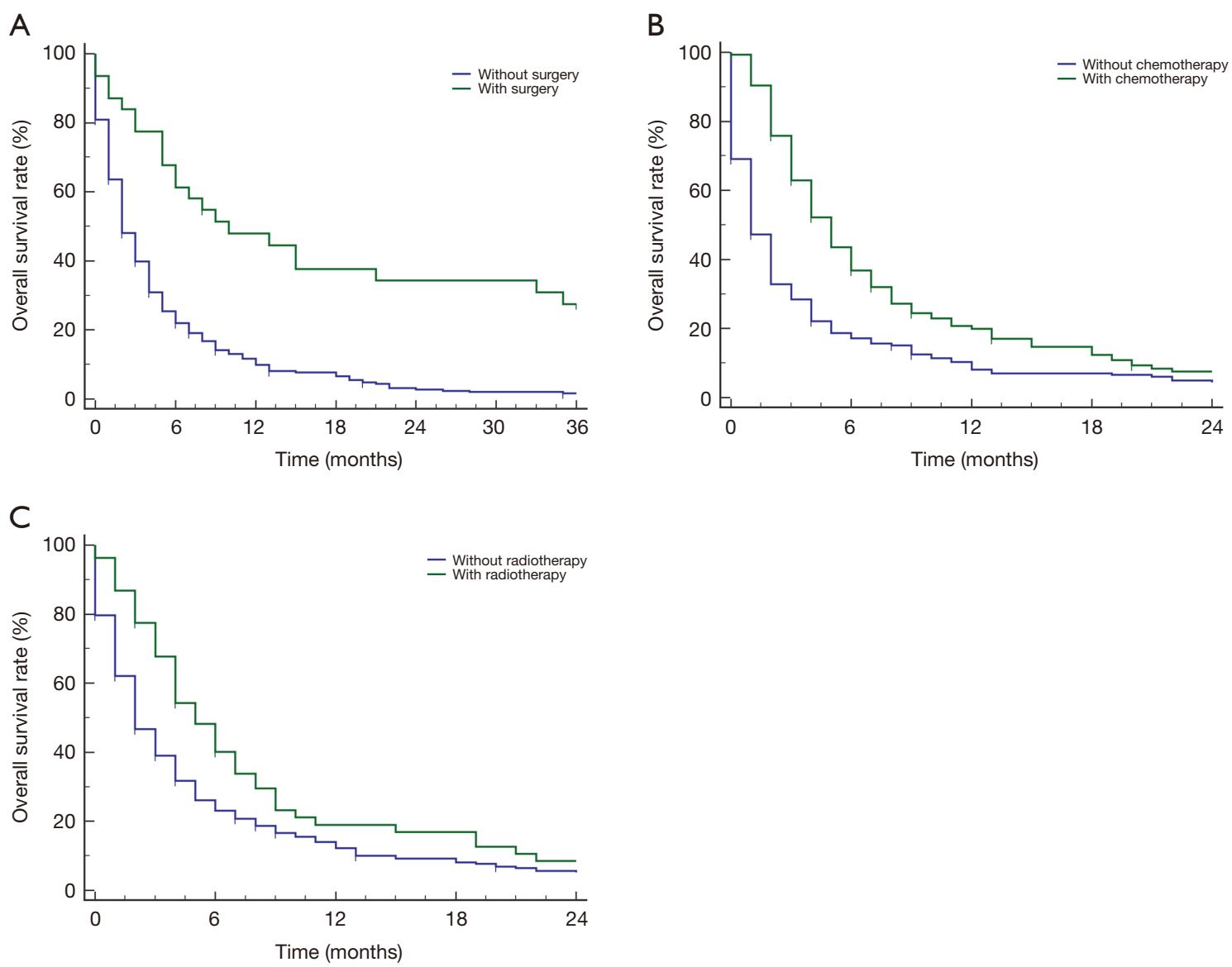

Figure 3 the effect of treatment method on prognosis in SCCP patients. (A) surgery; (B) chemotherapy; (C) radiotherapy. SCCP, squamous cell carcinoma of pancreas.

affect both sexes equally (2). In the present study, also no sex preference could be observed in the present cohort of 373 SCCP patients (175 men and 198 women). Previous studies showed that the anantomic head, tail and body of the pancreas were affected equally by SCCP $(2,10,15)$. In the present study, $42.9 \%$ of cases was located in the head of pancreas $13.4 \%$ in the body as well as $17.9 \%$ in the tail. And $8 \%$ of cases had overlapping lesion of the pancreas due to tumor may span more than one portion of the organ. The survival analysis showed that no difference in overall survival among different site of pancreas. Previous study reported that the biological behavior of SCCP present to be similar to PDCA. Approximately $95 \%$ of patients show evidence of disseminated or locally metastatic disease at the time of initial evaluation or laparotomy, with the regional lymph nodes, liver, lung, and bones being most commonly affected $(10,11,13)$. In consistent with this data, our study showed that $94.2 \%$ of patients were diagnosed with regional stage and distant stage. Among all patients with metastases information, 100/214 patients had lymph node metastases and $154 / 243$ patients had distant metastases.

The treatment regimen for SCCP is limited, but surgical resection, chemotherapy and radiotherapy could improve prognosis for SCCP patients. For example, Brown HA's study reported a median survival of 7.0 months for patients who received surgery and only 3 months for those who did not receive surgery (2). Gruhl et al. reported that SCCP patients undergoing surgical resection had significantly longer median OS than those without surgery (21.3 vs. 6.8 months) (16). Tella et al.'s study observed that median OS for SCCP patients was 4 months and was significantly higher in patients who underwent surgical resection (17.0 vs. 4.0 months) (17). Combined with the previous studies, SCCP patients had 1-year and 5-year survival rates of $4.8 \%$ and $1 \%$ respectively (3). In consistent with this data, our study also reported the median survival of 10.0 months 
Table 2 Univariate and multivariate Cox proportional hazard analyses of the clinical characteristics for prognosis in SCCP patients

\begin{tabular}{|c|c|c|c|c|c|}
\hline Factor & Category & \multicolumn{2}{|c|}{ Univariate } & \multicolumn{2}{|c|}{ Multivariate } \\
\hline Age, years & $>69 / \leq 69$ & $1.27(1.03-1.57)$ & 0.02 & $1.01(0.8-1.26)$ & 0.90 \\
\hline Gender & Male/female & $1.08(0.81-1.44)$ & 0.61 & & \\
\hline \multirow[t]{2}{*}{ Race } & White & Reference & & & \\
\hline & Other & $0.93(0.65-1.33)$ & 0.67 & & \\
\hline \multirow[t]{3}{*}{ Pathological differentiation } & Well & Reference & & & \\
\hline & Moderate & $1.35(0.62-2.93)$ & 0.45 & & \\
\hline & Poor & $1.48(0.75-2.93)$ & 0.26 & & \\
\hline \multirow{2}{*}{ Summary stage } & Regional & $1.27(0.74-2.17)$ & 0.39 & & \\
\hline & Distant & $2.04(1.21-3.41)$ & $<0.01$ & & \\
\hline \multirow[t]{4}{*}{ Primary site } & Head of pancreas & Reference & & & \\
\hline & Body of pancreas & $0.98(0.71-1.37)$ & 0.93 & & \\
\hline & Tail of pancreas & $0.99(0.73-1.34)$ & 0.94 & & \\
\hline & Overlapping lesion of pancreas & $1.35(0.89-2.04)$ & 0.15 & & \\
\hline \multirow[t]{2}{*}{ T stage } & $\mathrm{T} 1$ & Reference & & & \\
\hline & T2 & $1.21(0.16-8.69)$ & 0.85 & & \\
\hline Radiation & Yes/no & $0.68(0.51-0.93)$ & 0.01 & $0.77(0.57-1.06)$ & 0.11 \\
\hline Chemotherapy & Yes/no + unknown & $0.56(0.45-0.70)$ & $<0.01$ & $0.54(0.43-0.68)$ & $<0.01$ \\
\hline
\end{tabular}

SCCP, squamous cell carcinoma of pancreas.

and 2.0 months for patients who receive cancer-directed surgery or not, respectively. Similarly, the SCCP patients from our study had 1-year and 5-years survival rate were $13.2 \%$ and $1.8 \%$, respectively (18-20). However, SCCP is often metastatic or locally advanced at time of diagnosis, making resection impossible in most SCCP patients. Katz et al. reported the use of chemo-radiation could improve significantly prognosis in the palliative setting, but not adjuvant therapy (21). Tella et al.'s study demonstrated that stage IV patients treated with chemotherapy had a better OS than those without chemotherapy $(5.0 \mathrm{vs}$. 2.0 months) (17). In the present study, both patients with radiotherapy and chemotherapy had a significant longer mOS than those without radiotherapy or chemotherapy. Meanwhile, previous study demonstrated different chemotherapeutic agents had different influence on prognosis. For example, previous reports suggested regimens including bleomycin, or gemcitabine could have an improved response $(8,22)$. To date, no standard chemotherapy regimen has been established for SCCP and 
further investigation is required. Besides, previous reported have suggested that SCCPAg could be used as an important biomarker for diagnosis and monitor of tumor recurrence in SCCP patients (23), but we could not evaluate these due to inadequate information from SEER database.

Similar to other studies using SEER as a data source, there are several limitations. First, there are inadequate information about TNM stage and chemotherapy in the present cohort. For example, 136 out of 373 patients lacked TNM stage information. Two hundred and fourteen patients out of 373 patients have no accurate information about chemotherapy. Second, the data about other potential variables are lack, such as performance status, tumor size and gene alterations which limit the accurate interpretation of these results. Third, surgery methods and chemotherapy regimens were unknown, and the effect of potential advances in chemotherapy could not be evaluated, thus limiting our ability to describe treatment patterns for SCCP patients.

In conclusion, we performed a population-based study to yield a crude stratification of prognoses for SCCP patients based on the data from SEER database. The results showed that the prognosis of SCCP patients was poor with a mOS of only $3.0 \mathrm{~m}$, and distant metastases were independent prognostic factors of worse survival in SCCP patients, surgery and chemotherapy were independent protective factors. The present study was the largest series investigating the clinical characteristics and outcomes of SCCP patients to date and provide some useful information for future management and prospective studies for SCCP patients.

\section{Acknowledgments}

We thank LetPub (www.letpub.com) for its linguistic assistance during the preparation of this manuscript. Funding: None.

\section{Footnote}

Reporting Checklist: The authors have completed the STROBE reporting checklist. Available at http://dx.doi. org/10.21037/gs-20-317

Conflicts of Interest: All authors declare that there is no conflict of interest (available at http://dx.doi.org/10.21037/ gs-20-317). The authors have no conflicts of interest to declare.

Ethical Statement: The authors are accountable for all aspects of the work in ensuring that questions related to the accuracy or integrity of any part of the work are appropriately investigated and resolved. The study was conducted in accordance with the Declaration of Helsinki (as revised in 2013).

Open Access Statement: This is an Open Access article distributed in accordance with the Creative Commons Attribution-NonCommercial-NoDerivs 4.0 International License (CC BY-NC-ND 4.0), which permits the noncommercial replication and distribution of the article with the strict proviso that no changes or edits are made and the original work is properly cited (including links to both the formal publication through the relevant DOI and the license). See: https://creativecommons.org/licenses/by-nc-nd/4.0/.

\section{References}

1. Baylor SM, Berg JW. Cross-classification and survival characteristics of 5,000 cases of cancer of the pancreas. J Surg Oncol 1973;5:335-58.

2. Brown HA, Dotto J, Robert M, et al. Squamous cell carcinoma of the pancreas. J Clin Gastroenterol 2005;39:915-9.

3. Brayko CM, Doll DC. Squamous cell carcinoma of the pancreas associated with hypercalcemia. Gastroenterology 1982;83:1297-9.

4. Pradhan SA, Rajpal RM, Kothary PM. Surgical management of postradiation residual/recurrent cancer of the base of the tongue. J Surg Oncol 1980;14:201-6.

5. Alajlan BA, Bernadt CT, Kushnir VM. Primary Squamous Cell Carcinoma of the Pancreas: a Case Report and Literature Review. J Gastrointest Cancer 2019;50:130-3.

6. Al-Shehri A, Silverman S, King KM. Squamous cell carcinoma of the pancreas. Curr Oncol 2008;15:293-7.

7. Ben Kridis W, Khanfir A, Toumi N, et al. Primary squamous cell carcinoma of the pancreas: a report of two cases and review of the literature. Intern Med 2015;54:1357-9.

8. Anagnostopoulos GK, Aithal GP, Ragunath K, et al. Squamous cell carcinoma of the pancreas: report of a case and review of the literature. JOP 2006;7:47-50.

9. Brijbassie A, Stelow E, Shami VM. Squamous Cell Carcinoma of the Pancreas: A Case Report and Review of Literature. Gastroenterology Res 2014;7:102-4.

10. Itani KM, Karni A, Green L. Squamous cell carcinoma of the pancreas. J Gastrointest Surg 1999;3:512-5.

11. Beyer KL, Marshall JB, Metzler MH, et al. Squamous cell 
carcinoma of the pancreas. Report of an unusual case and review of the literature. Dig Dis Sci 1992;37:312-8.

12. Bralet MP, Terris B, Bregeaud L, et al. Squamous cell carcinoma and lipomatous pseudohypertrophy of the pancreas. Virchows Arch 1999;434:569-72.

13. Bringel RW, Souza CP, Araujo SE, et al. Squamous cell carcinoma of the pancreas with gastric metastasis. Case report. Rev Hosp Clin Fac Med Sao Paulo 1996;51:195-7.

14. Makarova-Rusher OV, Ulahannan S, Greten TF, et al. Pancreatic Squamous Cell Carcinoma: A Population-Based Study of Epidemiology, Clinicopathologic Characteristics and Outcomes. Pancreas 2016;45:1432-7.

15. Mulkeen AL, Yoo PS, Cha C. Less common neoplasms of the pancreas. World J Gastroenterol 2006;12:3180-5.

16. Gruhl JD, Garrido-Laguna I, Francis SR, et al. The impact of squamous cell carcinoma histology on outcomes in nonmetastatic pancreatic cancer. Cancer Med 2020;9:1703-11.

17. Tella SH, Kommalapati A, Yadav S, et al. Survival and prognostic factors in patients with pancreatic squamous

Cite this article as: Qin WX, Wu Y, Liu J, Qin BD, Liu K, Jiao XD, Wang Z, Chen WS, Zang YS. Primary squamous cell carcinoma of pancreas: a population-based study. Gland Surg 2021;10(3):1029-1037. doi: 10.21037/gs-20-317 cell carcinoma. Eur J Surg Oncol 2019;45:1700-5.

18. Colarian J, Fowler D, Schor J, et al. Squamous cell carcinoma of the pancreas with cystic degeneration. South Med J 2000;93:821-2.

19. Koduri VG, Ravi TJ. Squamous-cell carcinoma of the pancreas: report of a case and review of ERCP findings. Endoscopy 1994;26:333-4.

20. Serafini F, Rosemurgy AS, 2nd, Carey LC. Squamous cell carcinoma of the pancreas. Am J Gastroenterol 1996;91:2621-2.

21. Katz MH, Wang H, Fleming JB, et al. Long-term survival after multidisciplinary management of resected pancreatic adenocarcinoma. Ann Surg Oncol 2009;16:836-47.

22. Ravry M, Moertel CG, Schutt AJ, et al. Treatment of advanced squamous cell carcinoma of the gastrointestinal tract with bleomycin (NSC-125066). Cancer Chemother Rep 1973;57:493-5.

23. Minami T, Fukui K, Morita Y, et al. A case of squamous cell carcinoma of the pancreas with an initial symptom of tarry stool. J Gastroenterol Hepatol 2001;16:1077-9. 


\section{Supplementary}
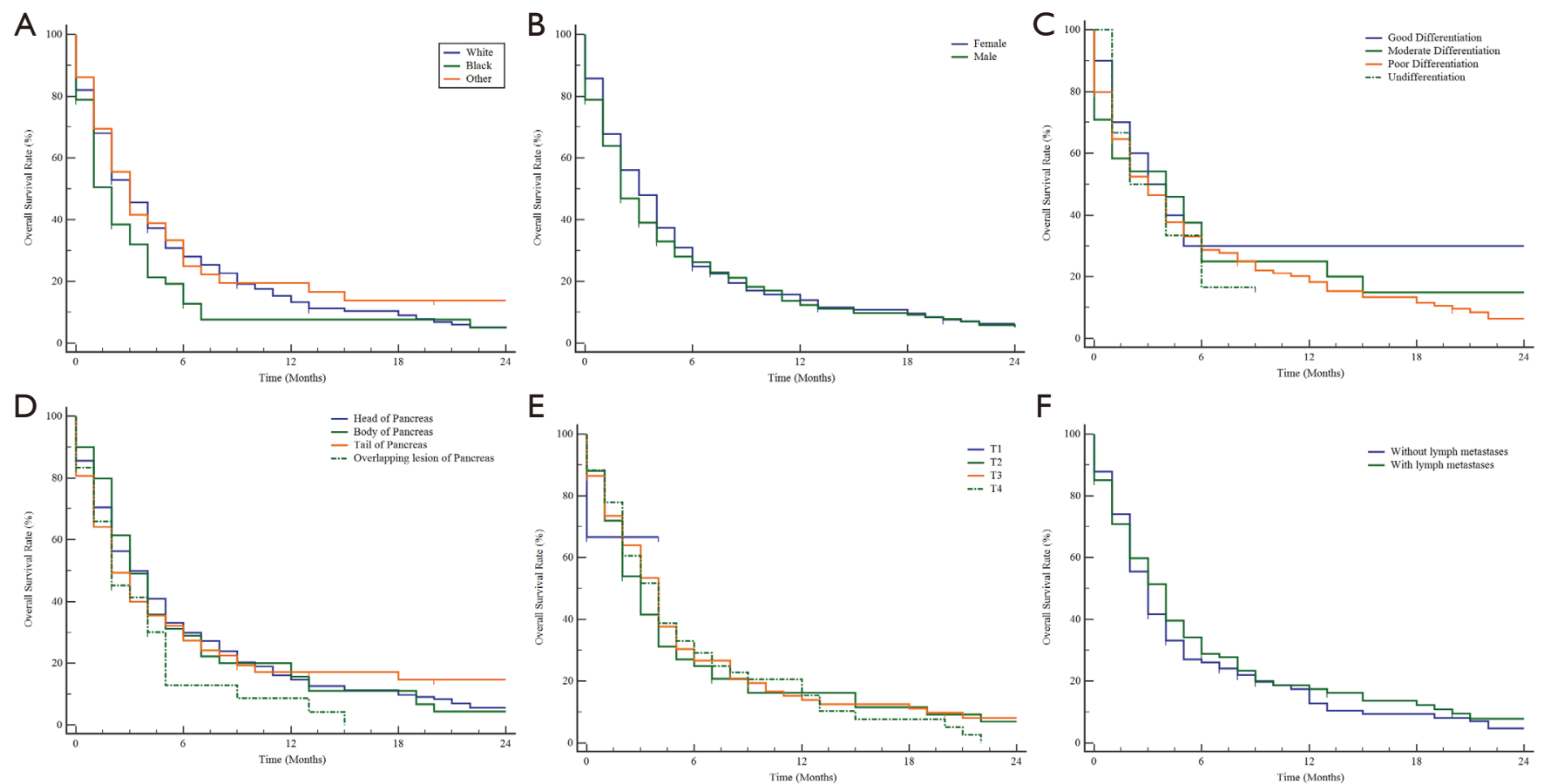

$\mathrm{F}$

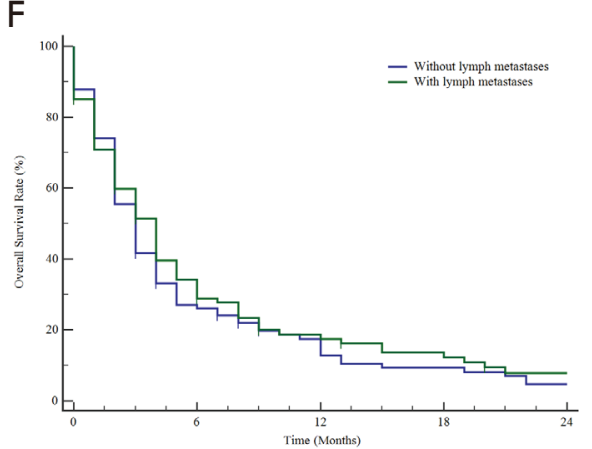

Figure S1 the effect of clinio-pathological features on prognosis in SCCP patients. (A) race; (B) gender; (C) pathological grade; (D) lesion site; (E) T stage; (F) N stage. SCCP, squamous cell carcinoma of pancreas. 